\title{
The Use of Educational Web Tools: An Innovative Technique in Teacher Education Courses
}

\author{
Ava Clare Marie O. Robles \\ College of Education, Mindanao State University, General Santos City, Philippines \\ Email: ava_robles@yahoo.com
}

\begin{abstract}
With the increasing dependence on internet sources, educational web tools have offered teachers with various opportunities to investigate the most appropriate educational tools to suit their students' learning preferences. Undeniably, students in this digital age need to learn how to effectively and efficiently create, collaborate and share new information on the web through the use of different tools available on the web for lifelong learning.
\end{abstract}

In response to this need, an empirical study on educational web tools as a technique to enhance student's learning was conducted. Hence, the aim of this paper was to determine the students' attitudes, skills and benefits they may have experienced during the conduct of their web tool activities in selected education subjects.

The results showed that students demonstrate positive attitudes on the use of educational web tools. Results further revealed that the students' skills and the benefits they have experienced differ according to their attitudes toward the use of educational web tools in the subject. Based from the findings, conclusion has been drawn regarding the use of educational web tools to support the teaching-learning process.

Finally, this paper is supported by an actual student's output, which can be found in the website (http://robles2011.blogspot.com/).

Index Terms - Educational Web Tools, Innovative Technique, Technology

\section{INTRODUCTION}

The development and rapid growth of Internet had brought several transformations in today's teachinglearning process. These changes increase the potential of a typical learner to do something that is more than what is expected from him. This enables the learners to become fast learners and fast thinkers. As new technology tools are launched, educators will have the opportunity to integrate these new tools into the courses to enhance instruction. Wikis, etudes, and other educational web tools may be employed to increase its effectiveness.
Further, as technology improves, educational capability increases correspondingly. These progressions in technology have persuaded the educators to find new ways to integrate technology into the course as an extension of their course outline in order to enhance the instructional experience and promote communication among their students $[1,2]$. With the growing reliance on the internet, Educational Web Tools (EWT) has presented teachers various opportunities to improve students' learning suitable to their learning preferences. Moreover, these EWT may be used as a teacher's innovative technique to maximize learning that pushes the learners to employ higher order thinking skills in the process.

Educational Web Tools (EWT) just like any Web 2.0 content are characterized by open communication, freedom to share and re-use content and dynamic interactivity among users of varying technical abilities around the globe. There are now a multitude of Webbased tools available that can allow people to organize their favorite bookmarks, write online documents, and share information with others through social software like blogs and wikis. These tools can positively impact teaching and learning, and the implications are significant. Students can be empowered to see how their ideas can be shared easily with the world, and students around the globe can easily collaborate and communicate with each other to build knowledge communities that are not dependent on time and space [3].

Educators at all levels are now encouraged to innovate. Concurrently, the use of EWT in teacher education courses creates stimulating chance for better collaboration between students and faculty. Some studies suggested that one of the means to innovate is through the use of EWT, which opens the opportunity for educators to make some changes in the classroom dynamics. With this in mind, embarking on studies using educational web tools is imperative. Thus, this study was undertaken to find out the students' attitudes towards various educational web tools as well as to determine their level of learning and thinking skills. This study employed the descriptive-comparative method. It investigated the significant difference in the level of learning and thinking skills of students across teacher education courses experienced by the one-hundred 
ninety (190) BSED students in Mindanao State University, General Santos City, Philippines. Specifically, the study sought to answer the following questions:

1. What attitudes do students have towards various educational web tools?

2. What is the level of learning and innovation skills of the students in terms of:

a. Creativity and Innovation;

b. Critical Thinking and Problem Solving; and

c. Communication and Collaboration

3. Is there a significant difference in the level of learning and thinking skills of students across teacher education courses?

4. What are the benefits gained from educational web activities as innovative tools in teacher education courses among MSU-BSED students?

5. Is there a significant difference on the benefits gained from educational web activities as innovative tools in teaching teacher education courses among MSU-BSED students?

\section{RELATED STUDIES}

The ever-speeding technological advancements drive numerous institutions to be in the cutting-edge. In order for these schools to stay fit for the challenges of the $21 \mathrm{st}$ century, innovative techniques that encompass all aspects of lifelong learning must be sought by educators in this century.

The use of EWT can be an ideal avenue for lifelong learning because it maintains interactive and collaborative learning. This provides students' learning experiences appropriate to this digital age. Additionally, EWT usage allows students to gain educational experiences that go beyond the four corners of the classroom. This type of innovation is very helpful and pertinent to universities worldwide that are in the stage of advancing their curriculum.

One useful feature of EWT, just like any Web 2.0 technology, is that it makes online collaboration possible. Users themselves (instead of the web page author) are able to edit, comment, create, and share content with other users. This collaborative feature of Web 2.0 comes along at a propitious time because many sources are increasingly considering collaboration to be an important factor in the success of educational, social, and technological endeavors, especially those pertaining to the web [4].

Moreover, Web 2.0 tools support self-presentation and thereby put more focus on the individual learner than traditional web-based learning management systems. Web 2.0 tools support a more playful and experimental approach to learning, and allow learners to present themselves and their insights in original ways. Personal blogs can be used as individual home page, which can be used for setting up learning plans and diaries, for showcasing work and documenting competences, and as a personal repository of links and resources the user frequently consults for learning and leisure [5].

\section{METHODOLOGY}

This study utilized the descriptive-comparative research design. It compared the difference in the level of learning and thinking skills of students across teacher education courses as well as the significant difference on the benefits gained from educational web activities as innovative tools in teaching teacher education courses among MSU-BSED students. Similarly, it described the benefits gained from educational web activities.

The respondents of the study were the one-hundred ninety (190) BSED students in Mindanao State University, General Santos City, Philippines, who were enrolled in Human Growth Learning and Development (Ed 102) Course, Assessment of Student Learning (Ed 103) Course, and Principles and Methods of Teaching (Ed 107) Course, Academic Year 2010-2011.

The main teaching methods involve lecture, in-class discussion and hands-on experience with the integration of various EWT in which students could (1) acquire outlines of the course material including PowerPoint presentations of theoretical lectures, description and rubrics of the projects, (2) take online quizzes and tests (using QUIA ), (3) design their EWT to discuss or give reflection on the topic discussed by the instructor every week, and (4) link to other websites related to the course content. As follows were the different activities made.

The instruments used in this study were adopted from Robles [6] and Partnership for 21st Century Skills Organization [7]. These instruments determine the attitudes that students have towards various educational web tools and the level of learning and innovation skills of the students.

However, possible benefits that students gained were collected through a free response question in a reflective survey. All data gathered were processed, presented, analyzed and interpreted using 5-scaled weighted mean and ANOVA for the significant difference. Based on the findings of the study the researcher formulated the conclusions and recommendations of the study. 


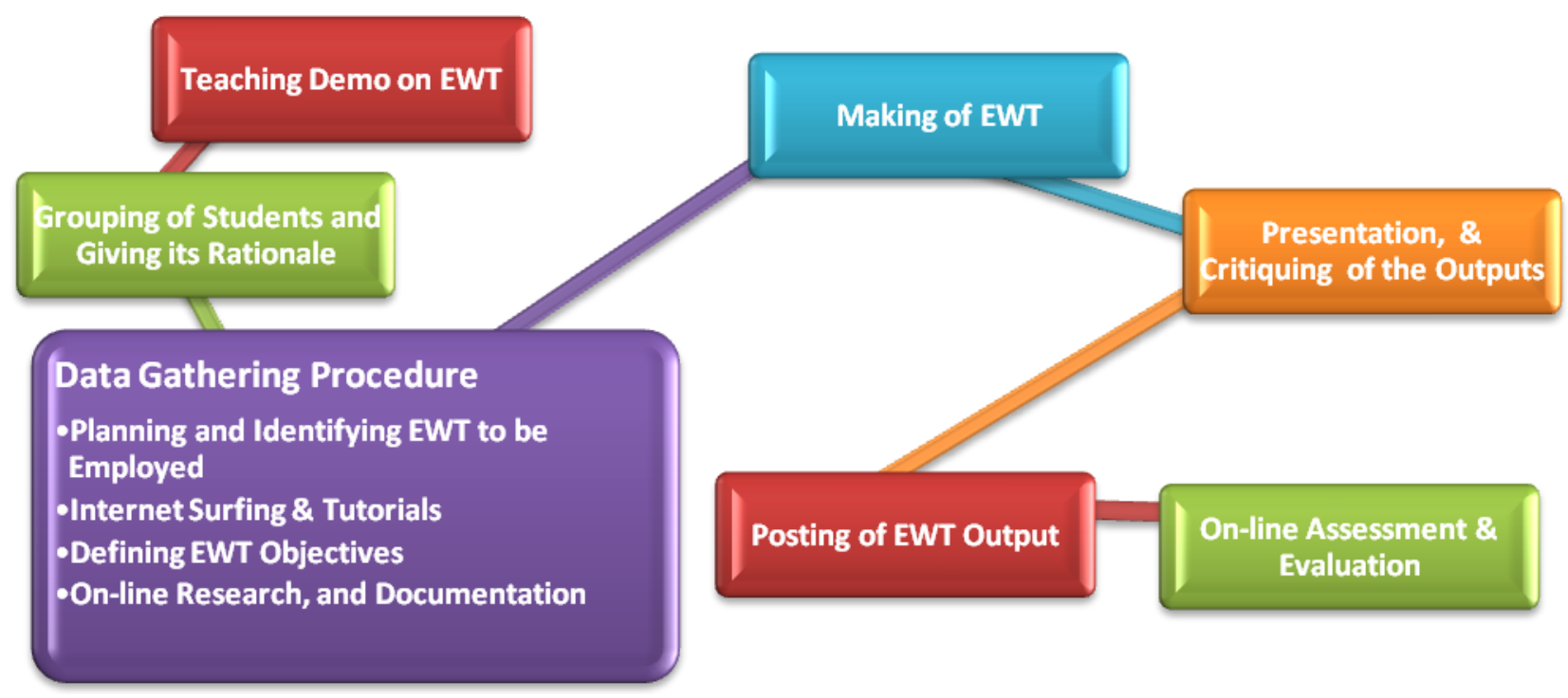

Figure 1. The EWT Development Process

\section{FINDINGS}

Table 1 shows the attitude of students toward various educational web tools. The study revealed that they appreciate the use of EWT in my education courses (wm = 4.5); they like EWT because they develop their higher order thinking skills $(\mathrm{wm}=4.3$ ) and that through EWT, they discovered that enhancing their technology skills is very significant in their life $(\mathrm{wm}=4.21)$. These results disclosed that they have a "Very Positive Attitude" on the use of EWT in their education courses. This means that the students found EWT as useful tools that add value to conventional teaching-learning process, and indulge different types of learners. Likewise, a person who is good at EWT has a great chance to succeed in other fields ( $w m=3.4)$; and spending more time learning the subject because of EWT $(\mathrm{wm}=3.6)$ indicated that students have "Positive Attitude" towards it.

Generally, an overall weighted mean of 3.99 showed that the students have a "Positive Attitude" towards EWT. This result agrees with the study of Kay [8] who explored the influence of context on attitudes towards web-based learning tools.

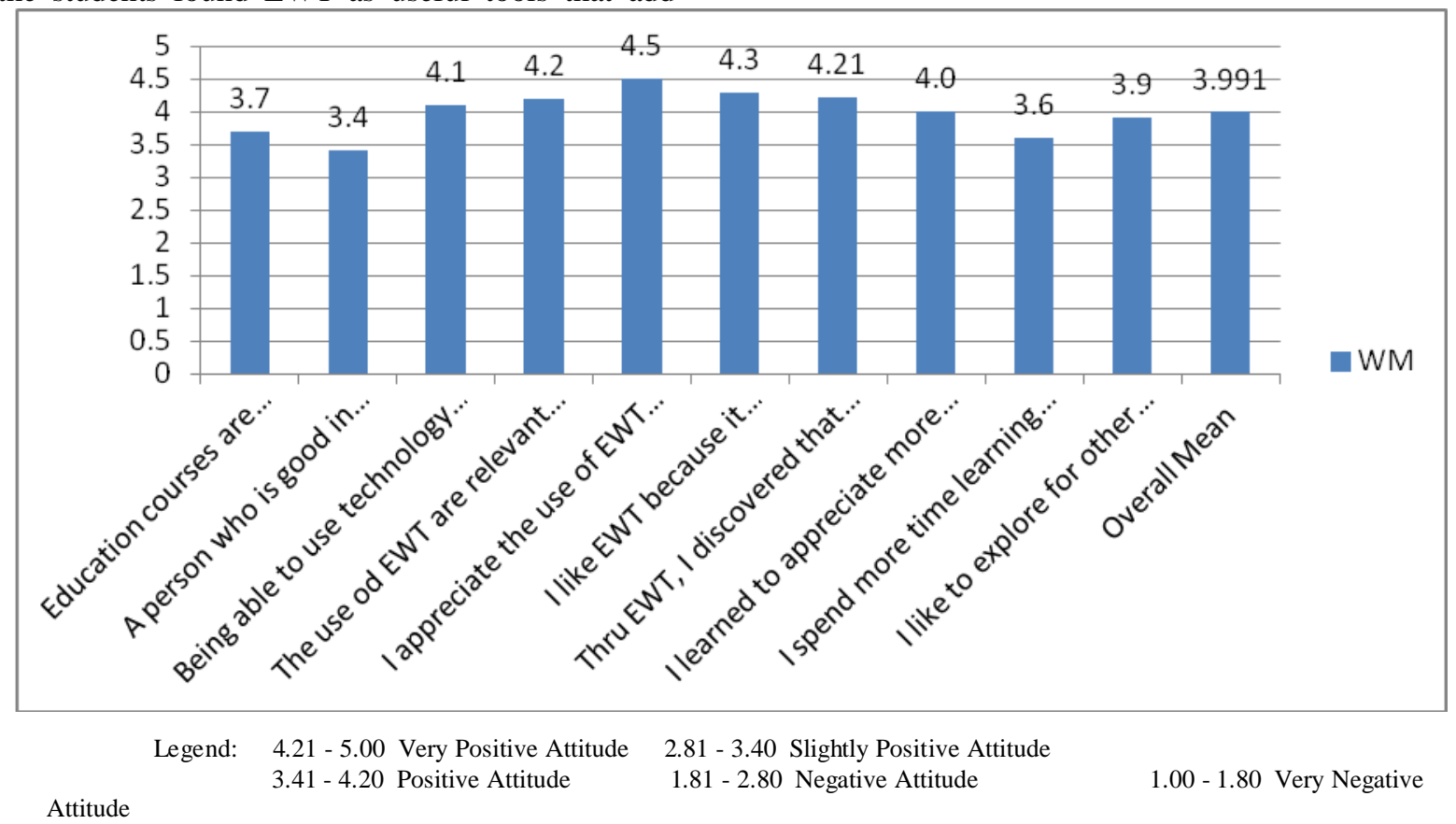

Figure 2. Students' Attitudes toward Various Educational Web Tools (EWT) 


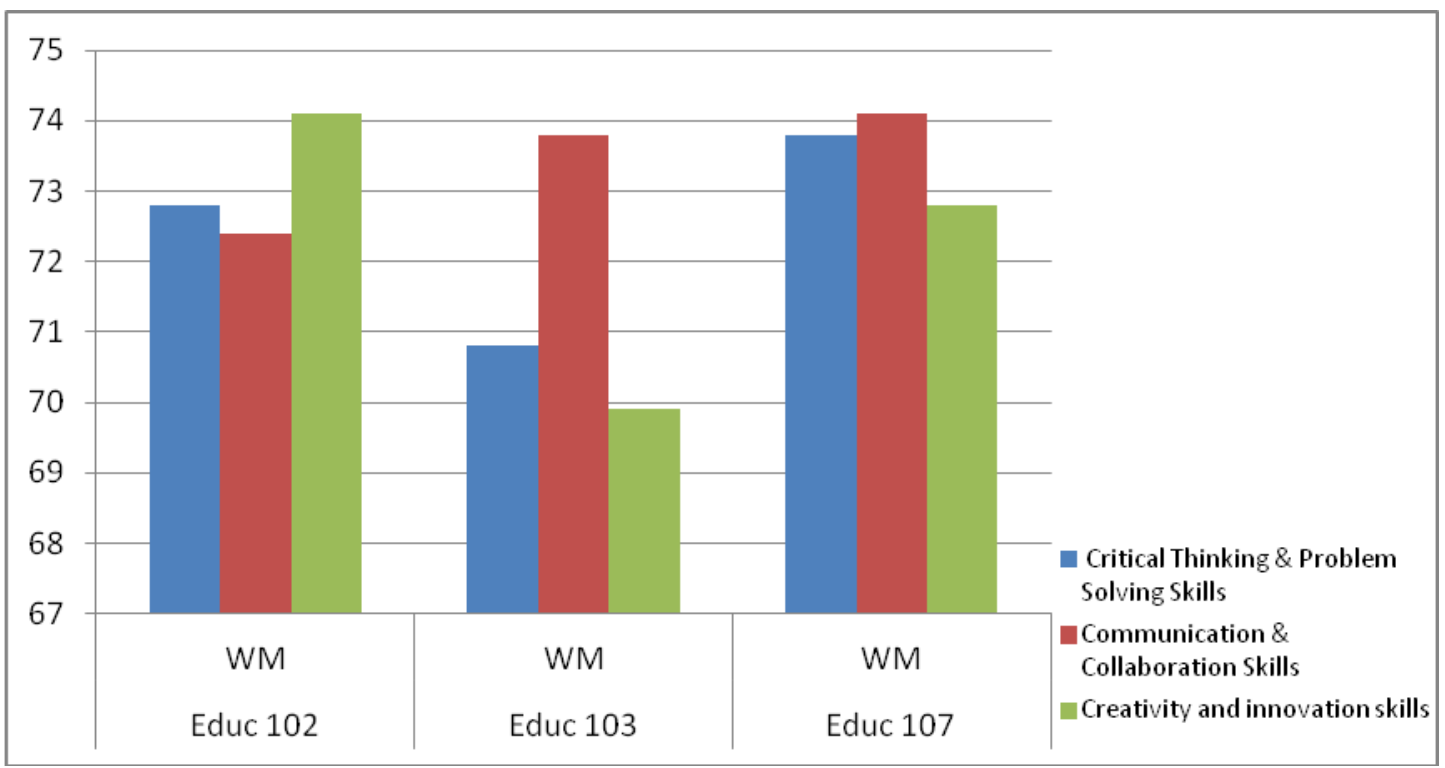

Figure 3.Level of Learning \& Innovation Skills of Students according to Courses

Data show that the learning \& innovation skills of students got the overall mean score of 72.7 described as "Nearing Mastery". But among them, communication \& collaboration skills have the highest mean score of 73.43 critical thinking \& problem solving skills, 72.5 and creativity and innovation skills have the lowest mean score of 72.3 The result of this study supports the study conducted by Peals, M., \& Morris, E. [9] where students' perceptions of online learning were also nearing mastery. This means that students were not able to master the different learning \& innovation skills expected of them.

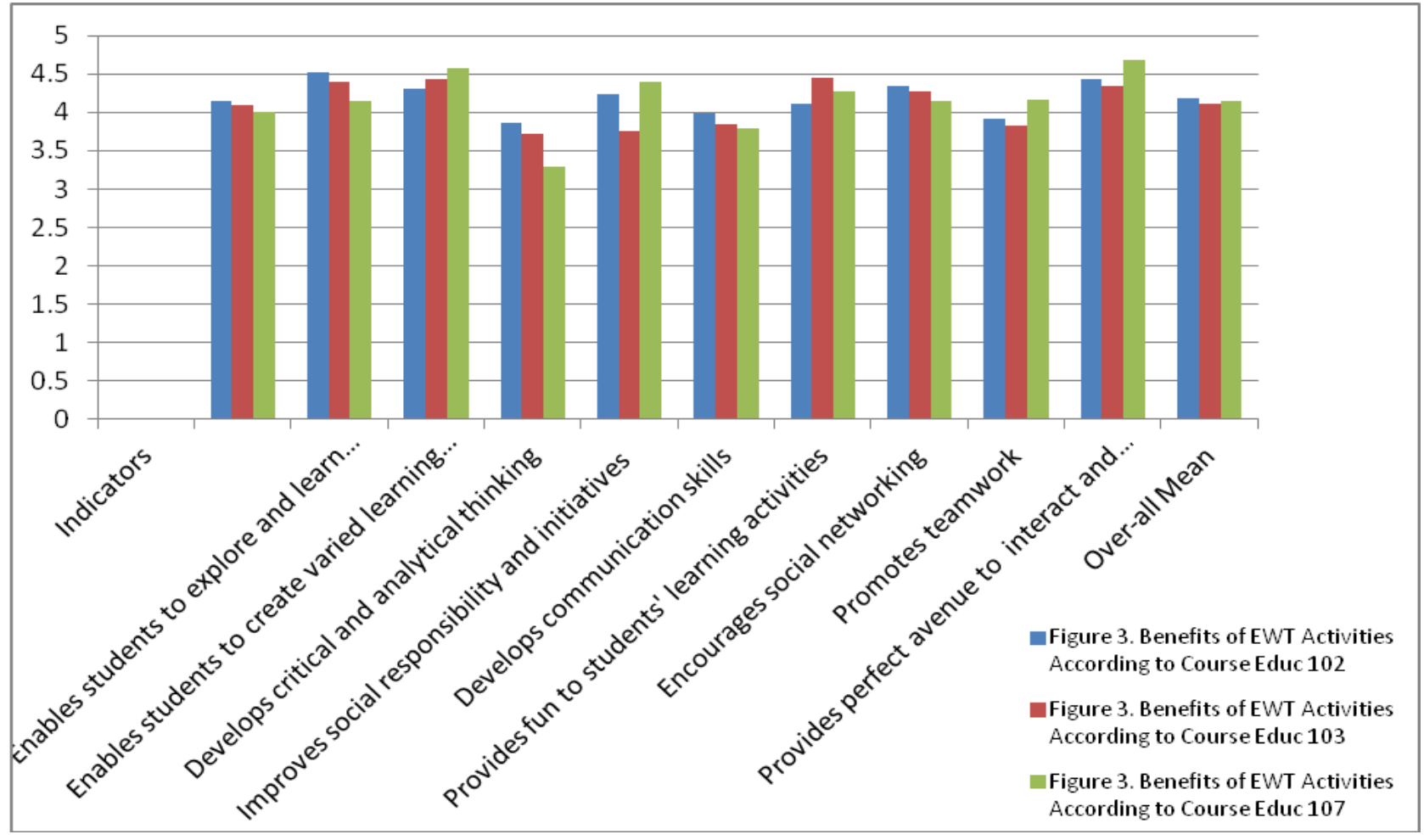

Figure 4. Perceived Benefits of EWT Activities according to Courses

Figure 4 presents the benefits of using EWT as an innovative technique in teaching education courses. The results of the study reveal a mean score of 4.49 indicating that EWT provides perfect avenue to interact and collaborate with other students and teachers as perceived by students. Likewise, a weighted mean of 4.4 ,
4.3 and 4.1 respectively indicate that EWT enable students to explore, and learn ideas from the web; promote social networking skills; and provide fun to students' learning activities. To summarize, the results showed that educational web tools have provided "Great Benefit" to students' learning. 
Table 1. Significant Difference in the Level of Learning \& Innovation Skills of Students across Courses

\begin{tabular}{|c|c|c|c|c|c|c|c|}
\hline \multirow{3}{*}{$\begin{array}{c}\text { Learning \& } \\
\text { Innovation Skills }\end{array}$} & \multicolumn{5}{|c|}{ Teacher Education Courses } & \multirow{3}{*}{ Remark } & \multirow{3}{*}{ Decision } \\
\hline & Ed 102 & Ed 103 & Ed 107 & \multirow{2}{*}{$\begin{array}{l}\mathrm{F}- \\
\text { ratio }\end{array}$} & \multirow{2}{*}{$\begin{array}{c}\mathrm{p}- \\
\text { value }\end{array}$} & & \\
\hline & $\bar{x}$ & $\bar{x}$ & $\bar{x}$ & & & & \\
\hline $\begin{array}{c}\text { Critical Thinking \& } \\
\text { Problem Solving Skills }\end{array}$ & 20.7 & 21.17 & 21.05 & 0.24 & 0.787 & $\begin{array}{c}\text { Not } \\
\text { Significant }\end{array}$ & Accept $H_{0}$ \\
\hline $\begin{array}{l}\text { Communication \& } \\
\text { Collaboration Skills }\end{array}$ & 21.0 & 21.57 & 21.30 & 0.35 & 0.705 & $\begin{array}{c}\text { Not } \\
\text { Significant }\end{array}$ & Accept $H_{0}$ \\
\hline $\begin{array}{c}\text { Creativity and } \\
\text { innovation skills }\end{array}$ & 20.81 & 21.3 & 21.10 & 0.48 & 0.043 & Significant & Reject $H_{0}$ \\
\hline
\end{tabular}

Table 1 shows that only the creativity \& innovation skills have significant difference in the learning and innovation skills of the students since the F-ratio of 0.35 has $\mathrm{p}>05$ (.705). Furthermore, it is also noted that other skills like critical thinking \& problem solving skills as well as communication \& collaboration skills, were not significantly different since their $\mathrm{p}$-values are greater than 0.05. These results indicate that there are no significant differences in their level of learning \& innovation skills across courses.

This adheres to the study of Lim, R. , \& Maddex, C. D. [10] that in order for students to perform better in education courses, their innovation skills should be harnessed by teachers by simply directing teaching methods towards creativity.

Table 2. Significant Difference on the Benefits Gained From Educational Web Activities as Innovative Tools in Teaching Teacher Education Courses

\begin{tabular}{|c|c|c|c|c|c|c|}
\hline \multicolumn{5}{|c|}{ Teacher Education Courses } & \multirow{2}{*}{ Remark } & Decision \\
\cline { 1 - 3 } Ed 102 & Ed 103 & Ed 107 & F-ratio & p-value & & \\
\hline $\bar{x}$ & $\bar{x}$ & $\bar{x}$ & & Not Significant & Accept $H_{0}$ \\
\hline
\end{tabular}

Table 2 shows a p-value of 0.749 that is greater than 0.05 , level of significance. This means that the benefits derived from the use of EWT for teaching education courses are not significantly different across Teacher Education Courses.

However, as highlighted in other studies the use of Internet for educational web activities has identified a number of benefits in using it for instruction such as convenience, speed of communication, quick and remote access to information, instant feedback, and cost saving $[11,12,13]$.

\section{CONCLUSIONS AND RECOMMENDATIONS}

In the light of the findings, the following conclusions could be made:

1. The students have a "Positive Attitude" towards educational web tools as an innovative technique in teacher education courses among MSU-BSED students.

2. The level learning \& innovation skills of students got the overall mean percentage of $72.7 \%$ described as "Nearing Mastery".
3. Only creativity \& innovation skills have significant difference in the learning and innovation skills of the students across teacher education courses.

4. Educational web tools used across teacher education courses have provided "Great Benefit" to students' learning.

5. The perceived benefits derived from the use of EWT as an innovative technique for teaching is not significantly different across teacher education courses.

In summary, it can be concluded that the EWTs are positively viewed by students and they seem to enhance the level of learning and innovation skills of the students in teacher education courses as well as supplement the conventional face-to-face classroom environment. Therefore, this style of innovative technique should be encouraged among faculty members. Additionally, the College of Education should take initiatives to implement EWT in its conventional courses to gain various benefits that boost students' learning experiences. Nevertheless, this will need effective planning and upgrading for educators to address critical issues such as establishing appropriate rubrics, determining effective EWT for the course, their content, 
and the style of communication among students and between students and teachers. Equally important is how learning and innovation skills could be further developed. These skills must be given focus in innovating because they will enable students to make intelligent decisions when using EWT, appreciate new learning experiences and finally improve their performance in the subject. The result of this finding is similar to the study of Malhiwsky [14] who highlighted that in order to encourage student achievement, colleges and universities must create courses both online and face-to-face which contain multiple Web 2.0 technologies. However, at this time, limited empirical research supporting the reliability or validity of these applications could be located.

This research endeavour represents the primary study providing insights on educational web tools as they affect students' skills, attitudes and achievement. As such, it presents two major implications. First, these findings suggest that employing educational web tools may significantly enhance students' skills. Further, it may likely change student's attitude with respect to their learning in teacher education courses. Research findings also suggest not all students have positive experiences in using educational web tools although they were greatly benefited from them.

In consideration of research results, an inference is that students who show positive attitude towards educational web tools as an innovative technique have higher level of learning \& innovation skills. The results further revealed that the students' skills and the benefits they have experienced differ according to their attitudes toward the use of educational web tools in the subject. A broader implication is that colleges may be moving toward utilizing more educational web tools for students when this research suggests that not all will be flourishing based on technology access, experience in using technology and actual use of educational web tools. Although these findings should be reviewed in consideration of study limitations, this research implies that educational web tools enhance teacher education courses. Since empirical evidence does not exist yet to support the reliability and validity of EWTs, academicians can only hypothesize as to their value. How much will students gain from this innovative technique? What institutional resources should be directed to these efforts? What is the cost/benefit analysis of these EWTs?

In view of the findings of this study, prospective research efforts could include studies designed to determine the effectiveness of specific educational web tools, specific combinations of educational tools and their applications. To determine the long-term value of educational web tools and to address issues associated with criterion and predictive validity, future studies might include a longitudinal component, analyzing the relationship between student achievement in EWTs enhanced courses and non-EWTs enhanced courses. Continued research on the level of facilitation by teachers in these courses should also be considered. Further developments to this study could embrace content specialists being consulted to improve course and assessment content thus enhancing content validity. To reduce threats to external validity, future studies might involve coordinated study efforts with numerous educational institutions exhibiting comparable demographic and school characteristics. To improve internal validity, other researchers might regard revisions in methodology dealing with issues of evaluation apprehension, selection bias, and sample size.

\section{ACKNOWLEDGMENT}

The author wishes to thank Professor Thelma Pagunsan, Dean of Bachelor of Secondary Department, College of Education, Mindanao State University, for her undying support to successfully complete this endeavor. Moreover, she wishes to thank all Bachelor of Secondary Students in Education who had been very supportive and efficient during the conduct of this study.

\section{REFERENCES}

[1] Karber, D. J. Comparisons and Contrasts in Traditional Versus On-Line Teaching in Management. Higher Education In Europe, 26(4), 533-536, 2001.

[2] Green, K. C. Campus computing, 1995. The sixth national survey of desktop computing in higher education. Encino, CA Campus Computing. (ERIC NO. ED 394 383), 1996.

[3] Wright, Cindy. Changing Education with Web 2.0 Tools. Retrieved on July 2011 (http://www.slideshare.net/lwright3768/changingeducation-with-web-20-tools). 2009.

[4] Lemley, Trey and Burnham, Judy F. Web 2.0 tools in medical and nursing school curricula. Retrieved on November 2011 (http://www.ncbi.nlm.nih.gov/pmc/articles/PMC260 5032/). 2008.

[5] Redecker, et.al. Learning 2.0: The Impact of Web 2.0 Innovations on Education and Training in Europe Retrieved on July 2011 from http://ftp.jrc.es/EURdoc/JRC55629.pdf. 2009.

[6] Robles, Ava Clare Marie O. Graduate School Cyber Portfolio: The Innovative Menu For Sustainable Development. Paper presented at Malaysia, Kuala Lumpur at 2011International Conference on Creativity \& Innovation For Sustainable Development, 2011.

[7] Partnership for 21st Century Skills. Retrieved on March 2011 from http://www.p21.org/overview/skills-framework, n.d.

[8] Kay, Robin. Exploring the Influence of Context on Attitudes toward Web-Based Learning Tools and Learning Performance. Interdisciplinary Journal of 
E-Learning and Learning Objects. Retrieved on December 2011 from http://www.ijello.org/Volume7/IJELLOv7p125142Kay748.pdf. 2011.

[9] Peals, M., \& Morris, E. Innovation Skills and Students' Online Behaviours: A study of student perceptions of online learning. Paper presented at the annual meeting of the Aisan Educational Research Association, Malaysia, 2003.

[10] Lim, R. , \& Maddex, C. D. Innovation Skills \& Student use of instructors' Web sites. Technology in Teacher Education 2001. NY, VA: Association for the Advancement of Computing in Education. Retrieved Sept 2003 from http://www.ny.wh.edu/insite/elecpub/html 2001/.

[11] Madden, A., Ford, N., Miller, D., \& Levy, P. (2005). Using the internet in teaching: the views of practitioners (A survey of the views of secondary school teachers in Sheffield, UK). British Journal of Educational Technology, 36(2), 255-280.
[12] Koch, C., \& Gobell, J. A hypertext -based tutorial with links to the Web for teaching statistics and research methods. Behavior Research Methods, Instruments, \& Computers, 31, 7-13.1999.

[13] Pychyl, T.A., Clarke, D., \& Abarbanel, T. Computer-mediated group projects: Facilitating collaborative learning with the World Wide Web. Teaching of Psychology, 26, 138-141. 1999.

[14] Malhiwsky, Dallas R.. "Student Achievement Using Web 2.0 Technologies: A Mixed Methods Study". Open Access Theses and Dissertations from the College of Education and Human Sciences. Paper 58. Retrieved on December 2011 from http://digitalcommons.unl.edu/cehsdiss/58. 2010.

Ava Clare Marie O. Robles is an Associate Professor IV in Mindanao State University, Philippines. She had been an International paper presenter in Thailand and Malaysia, and a Graduate School professor in Mindanao State University and Notre Dame of Marbel University. 